\title{
A pH-sensitive carrier based-on modified hollow mesoporous carbon nanospheres with calcium-latched gate for drug delivery
}

\author{
Asgari, Shadi ; Pourjavadi, Ali ; Hosseini, Seyed Hassan ; Kadkhodazadeh, Shima
}

Published in:

Materials Science and Engineering C: Materials for Biological Applications

Link to article, DOI:

10.1016/j.msec.2019.110517

Publication date:

2020

Document Version

Peer reviewed version

Link back to DTU Orbit

Citation (APA):

Asgari, S., Pourjavadi, A., Hosseini, S. H., \& Kadkhodazadeh, S. (2020). A pH-sensitive carrier based-on modified hollow mesoporous carbon nanospheres with calcium-latched gate for drug delivery. Materials Science and Engineering C: Materials for Biological Applications, 109, [110517].

https://doi.org/10.1016/j.msec.2019.110517

\section{General rights}

Copyright and moral rights for the publications made accessible in the public portal are retained by the authors and/or other copyright owners and it is a condition of accessing publications that users recognise and abide by the legal requirements associated with these rights.

- Users may download and print one copy of any publication from the public portal for the purpose of private study or research.

- You may not further distribute the material or use it for any profit-making activity or commercial gain

- You may freely distribute the URL identifying the publication in the public portal 


\section{Journal Pre-proof}

A pH-sensitive carrier based-on modified hollow mesoporous carbon nanospheres with calcium-latched gate for drug delivery

Shadi Asgari, Seyed Hassan Hosseini, Ali Pourjavadi, Shima Kadkhodazadeh

PII:

DOI:

Reference:

To appear in:

Received date:

Revised date:

Accepted date:
S0928-4931(19)33535-0

https://doi.org/10.1016/j.msec.2019.110517

MSC 110517

Materials Science \& Engineering $C$

20 September 2019

12 November 2019

1 December 2019

Please cite this article as: S. Asgari, S.H. Hosseini, A. Pourjavadi, et al., A pH-sensitive carrier based-on modified hollow mesoporous carbon nanospheres with calcium-latched gate for drug delivery, Materials Science \& Engineering C (2019), https://doi.org/10.1016/ j.msec.2019.110517

This is a PDF file of an article that has undergone enhancements after acceptance, such as the addition of a cover page and metadata, and formatting for readability, but it is not yet the definitive version of record. This version will undergo additional copyediting, typesetting and review before it is published in its final form, but we are providing this version to give early visibility of the article. Please note that, during the production process, errors may be discovered which could affect the content, and all legal disclaimers that apply to the journal pertain.

(C) 2019 Published by Elsevier. 


\title{
A pH-sensitive Carrier Based-on Modified Hollow Mesoporous Carbon
} Nanospheres with Calcium-Latched Gate for Drug Delivery

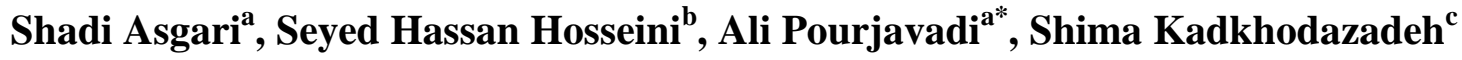 \\ ${ }^{a}$ Polymer Research Laboratory, Department of Chemistry, Sharif University of Technology, Tehran, Iran \\ ${ }^{b}$ Department of Chemical Engineering, University of Science and Technology of Mazandaran, Behshahr, Iran \\ ${ }^{c}$ National Center for Nano Fabrication and Characterization, Technical University of Denmark, 2800 Kgs. \\ Lyngby, Denmark
} Corresponding Author E-mail: purjavad@sharif.edu: Phone/Fax: (982)166165311

\begin{abstract}
A novel nanocarrier based-on hollow mesoporous carbon nanospheres (HMCNs) with primary amines on its surface, a large cavity, and good hydrophilicity was synthesized by a hydrothermal reaction. The primary amine functionalities on the mesoporous carbon were used as the initiation sites for growing poly(epichlorohydrin) ( $\mathrm{PCH})$ chains. The chlorine groups in the side chain of $\mathrm{PCH}$ were replaced with imidazole as the pendant groups. Calcium chloride $\left(\mathrm{CaCl}_{2}\right)$ was applied as a capping agent. The coordination bonding was formed between pendant imidazole groups and calcium ions. Doxorubicin (DOX) was selected as a model of hydrophilic anticancer drug and was loaded onto the nanocarrier and released through the cleavage of the $\mathrm{pH}$-sensitive coordination bonding. The gating mechanism enables the nanocarrier to store and release the calcium ions and the DOX molecules trapped in the pores. MTT assay toward HeLa cells indicated that the nanocarrier had low toxicity because of the surface modification with the oxygen-rich polymer. The cellular uptake of the $\mathrm{pH}$-sensitive nanocarrier for HeLa cancer cell lines was confirmed by CLSM images and flow cytometry. So, the novel $\mathrm{pH}$-sensitive nanocarrier can be applicable to carry and release both DOX drug and calcium ions for cancer treatment.
\end{abstract}


Keywords: Mesoporous hollow carbon nanospheres; Poly(epichlorohydrin); pH-sensitive; Coordination bonding; Doxorubicin

\section{1-Introduction}

Controlled and targeted drug delivery systems have been widely noticed for the medical applications[1]. There are various nanocarriers that have been developed for controlled drug delivery systems[2-13]. In the last few years, the mesoporous carbon spheres and hollow mesoporous carbon spheres have received much attention in various applications since they have high surface area, large pore volume, adjustable pore distribution, hollow space, special shape, low density, substantial biocompatibility, photothermal conversion capability, and high adsorption capacity[14-21]. Also, the mesoporous carbon spheres can be used for capturing and releasing of different guest molecules with various shapes, sizes, and functional groups[22, 23]. So far, few several nanocarriers based-on mesoporous carbon nanoparticles (MCNs) and hollow mesoporous carbon nanoparticles (HMCNs) have been developed for anticancer drug delivery because of low hydrophilicity of these nanoparticles [24-34]. So, MCNs are usually modified with oxygen-rich polymers such as polyethylene glycol (PEG) in order to increase water dispersibility, decrease cytotoxicity and immunogenicity, and improve prolonged body-residence time and reduced renal clearance as the pharmacokinetic and pharmacodynamic properties[35]. pH-sensitive systems are one kind of smart drug delivery systems which have been widely investigated[7, 9, 10, 36-41]. The capping $\mathrm{pH}$-sensitive systems have been developed recently for capturing the drug in the pores. The gating mechanism is able to store and release molecules trapped in the pores[42-48]. Several on/off capping or gating systems in the form of coordination bonding have been investigated[49-57]. Various metal ions have biological applications and play important biological roles as active centers for enzymes, proteins, and coenzymes. Calcium is a biologically active metal ion that is regulated in eukaryotic cells and plays an important role in orchestrating apoptosis. When 
calcium exists in the cell cytoplasm, it stimulates an apoptotic cycle $[58,59]$. So, A carrier that is able to deliver both drug molecules and calcium ions can be more efficient than the carrier that release only the drug and it can have the advantage of synergistic interactions[45]. Herein, we synthesized a novel $\mathrm{pH}$-sensitive nanocarrier based-on calcium-latched gates for capturing and releasing of DOX as a model of anticancer drug. In this work, hollow mesoporous carbon nanospheres were modified with poly(epichlorohydrin) (PCH) as an oxygen-rich polymer and imidazole as a side chain group The aim to choose the PCH was because of $\mathrm{C}-\mathrm{O}$ and $\mathrm{O}-\mathrm{H}$ groups that leads to increase the water dispersibility of the nanocarrier and also $\mathrm{Cl}$ pendant functionalities in the $\mathrm{PCH}$ chains can replace with imidazole groups to formation the coordination bonding between imidazole and calcium ions. The formation and cleavage of calcium ion-imidazole coordination bonds are sensitive to $\mathrm{pH}$ variations; since both calcium ions and protons are Lewis acids, they compete to interact with imidazole groups as the basic ligand. In comparison with the previous works [60-64], we used a hydrothermal reaction instead of high-temperature carbonization to prepare the mesopore carbon nanospheres with better hydrophilicity. Also, the prepared mesopore carbon spheres in previous works $[23,27,62,65]$ except some few researches in related to mesoporous silica structures $[49,52,53]$ have been used only for delivery the drug while this nanocarrier can be applied for delivery of both drug and metal ions.

\section{2- Experimental}

\section{2-1- Materials}

Tetraethyl orthosilicate (TEOS), ammonia solution $\left(\mathrm{NH}_{4} \mathrm{OH}, 25 \%\right)$, triethylamine (TEA), silver nitrate $\left(\mathrm{AgNO}_{3}\right)$, potassium chromate $\left(\mathrm{K}_{2} \mathrm{CrO}_{4}\right)$, epichlorohydrin, calcium chloride dihydrate $\left(\mathrm{CaCl}_{2} \cdot 2 \mathrm{H}_{2} \mathrm{O}\right)$, imidazole, ammonium fluoride, and sodium iodide were provided from Merck. Low molecular weight chitosan, boron trifluoride etherate, potassium permanganate $\left(\mathrm{KMnO}_{4}\right)$, silica nanoparticles, and DAPI (4',6-diamidino-2-phenylindole) 
were provided from Sigma-Aldrich. Doxorubicin hydrochloride (DOX) was purchased from Pfizer. The solvents including dimethylformamide (DMF), acetic acid, hydrofluoric acid (HF), and also MTT reagent [3-(4,5-dimethylthiazol-yl)-2,5-diphenyltetrazolium bromide] were purchased from Merck. HeLa cancer cells were received from Pasteur Institute, Tehran, Iran. Dialysis bags (molecular weight cutoff $12 \mathrm{kDa}$ ) were used in all of the release experiments.

\section{2-2-Instruments}

Fourier-transform infrared (FT-IR) spectroscopy was recorded on an ABB Bomem MB-100 spectrophotometer. Ultraviolet-visible (UV-Vis) spectra were collected by a Perkin-Elmer Lambda 25. The hydrodynamic diameter and zeta potential values of the nanospheres were measured in deionized water $(\mathrm{pH}=7.0)$ using Horiba SZ-100 nanoparticle size and zeta potential analyzer. Thermogravimetric analysis (TGA) of the samples was performed by a Mettler Toledo TG/DSC at a heating rate of $10{ }^{\circ} \mathrm{C} / \mathrm{min}$ from room temperature to $600{ }^{\circ} \mathrm{C}$ under $\mathrm{N}_{2}$ atmosphere. A scanning electron microscope (TESCAN FE-SEM MIRA3) was used for the analysis of morphology and elemental identification of the samples. Transmission electron microscopy (TEM) images were recorded using a FEI titan instrument operated at 300kV. Inductively coupled plasma-optical emission spectroscopy (ICP-OES, 730-ES, Varian) was applied for determination of the amount of coordinated calcium ions. BrunauerEmmett-Teller (BET) and Barrett-Joyner-Halenda (BJH) analyses were applied to measure the specific surface area, pore size distribution and pore volume on a MicrotracBEL Corp. The cellular uptake measurements were performed by confocal laser scanning microscopy (CLSM, Leica TCS 154SPE, Germany) and flow cytometry (BD FACSCalibur, San Jose, CA, USA) analyses.

\section{2-3- Synthesis of hollow mesoporous carbon nanospheres (HMCNs)}


HMCNs were synthesized according to the procedure reported by Xingyu Jiang, et al [26, 30]. The chitosan solution (100.0 mg in $20 \mathrm{~mL}$ DI water) containing acetic acid (200 $\mu \mathrm{L})$ was prepared and silica nanoparticles were dispersed it (Wchitosan: Wsilica $=1: 2$ ). The mixture was poured into the autoclave and sealed. The hydrothermal reaction was performed at 180 ${ }^{\circ} \mathrm{C}$ for $12 \mathrm{~h}$. The resulting product was placed into a buffer solution containing ammonium fluoride $(8 \mathrm{M})$ and hydrofluoric acid $(2 \mathrm{M})$ at $\mathrm{pH}=4$ for 3 days for dissolving the silica template. The resulting hollow mesoporous carbon nanospheres were washed several times by centrifugation and dried at room temperature.

\section{2-4- Synthesis of HMCNs functionalized with poly(epichlorohydrin) (HMCNs-PCH)}

At first, HMCNs $(10.0 \mathrm{mg})$ were sonicated in epichlorohydrin $(1 \mathrm{~mL})$ and refluxed at $60^{\circ} \mathrm{C}$ for $24 \mathrm{~h}$. The temperature was decreased to room temperature. $\mathrm{BF}_{3} \cdot \mathrm{Et}_{2} \mathrm{O}$ was added as a catalyst and the mixture was stirred at $0{ }^{\circ} \mathrm{C}$ by a mechanical stirrer. Then, epichlorohydrin $(3.0 \mathrm{~mL})$ was added slowly, and the mixture was further stirred for 4 days. Finally, the mixture was quenched and washed several times with methanol. The resulting product was dried at room temperature.

\section{2-4-1- Determination of chlorine content in HMCNs-PCH by alkaline fusion (sodium} fusion) method $[66,67]$

At the beginning, one piece of sodium metal was cut and placed in a tube and heated on a flame. Afterwards, HMCNs-PCH (4 mg) was put in the center of the fused sodium and heated on the flame again. Ethanol was poured into the tube for dissolving the excess sodium. Distillated water was transferred into the tube and ethanol was evaporated by heating for 20 minutes. The solution temperature was brought to the room temperature and the solution was filtrated. The filtrate solution was titrated with silver nitrate solution $(0.01 \mathrm{M})$ (Mohr method) in the presence of potassium chromate as an indicator for determining chloride 
concentration [68]. For the calculation, distillated water was titrated with $\mathrm{AgNO}_{3}$ solution $(0.01 \mathrm{M})$ and the chloride content in HMCNs-HPC was calculated to be about $3.5 \mathrm{mmol} / \mathrm{g}$.

\section{2-5-Synthesis of HMCNs-PCH modified with imidazole (HMCNs-PCH-p-I)}

The resulting HMCNs-PCH was sonicated in DMF $(5 \mathrm{~mL})$ solvent. Then, imidazole $(60.0$ $\mathrm{mg})$, triethylamine (TEA) $(0.1 \mathrm{~mL})$ and sodium iodide $(\mathrm{NaI})(20 \mathrm{mg})$ were added and the mixture was stirred at $90{ }^{\circ} \mathrm{C}$ for 3 days. In this process, a nucleophilic substitution between chlorine and imidazole functionalities occurs. The final product was separated by centrifugation and washed with DMF.

\section{2-6- Loading of DOX}

HMCNs-PCH-p-I $(10 \mathrm{mg})$ was sonicated in deionized water $(6 \mathrm{~mL})$. Then, DOX. HCl solution $(0.6 \mathrm{ml}, 2 \mathrm{mg} / \mathrm{mL})$ was added and stirred at room temperature for $24 \mathrm{~h}$ in a dark tube. The resulting HMCNs-PCH-p-I@D was centrifuged and washed by deionized water for removing free DOX. The concentration of DOX loaded to the HMCNs-PCH-p-I was determined by UV-Vis spectrophotometer at $480 \mathrm{~nm}$. Also, the same procedure was performed to loading of DOX into the HMCNs and the amount of DOX loaded to the HMCNs was determined by UV-Vis spectrophotometer at $480 \mathrm{~nm}$.

\section{2-7- Synthesis of calcium latched- HMCNs-PCH-p-I@D}

Formation of coordination bonding between calcium ions and amino-containing functional groups (imidazole) was performed by the following procedure. A solution of $\mathrm{CaCl}_{2} \cdot 2 \mathrm{H}_{2} \mathrm{O}$ in ethanol (0.01 M) was prepared and HMCNs-PCH-p-I@D (15 mg) were dispersed in the solution and stirred at room temperature for $24 \mathrm{~h}$. The amount of the coordinated calcium ion was $5.25 \mathrm{mg} / \mathrm{mL}$ as determined by ICP-OES. 


\section{2-8- Release of DOX}

The release of DOX from HMCNs@D, HMCNs-PCH-p-I@D, and calcium latched- HMCNsPCH-p-I@D was investigated at $37^{\circ} \mathrm{C}$ in phosphate buffer at $\mathrm{pH}=5.0$ and 7.4. A solution of calcium latched- HMCNs-PCH-p-I@D in deionized water $(5 \mathrm{mg}, 1 \mathrm{~mL})$ was prepared and placed in each of the buff er solutions $(1 \mathrm{~mL})$ in two separate dialysis bags. Then, the dialysis bags were put in the same buffers $(5 \mathrm{~mL})$ in dark tubes and were stirred at $37{ }^{\circ} \mathrm{C}$. At defined time intervals, $3 \mathrm{~mL}$ of the solution was withdrawn and $3 \mathrm{~mL}$ fresh buffer was replaced. The concentration of DOX was measured by UV-Vis spectrometery at $480 \mathrm{~nm}$. Also, DOX release of HMCNs@D and HMCNs-PCH-p-I@D was investigated by the same procedure and the concentration of DOX was measured by UV-Vis spectrometery at $480 \mathrm{~nm}$.

\section{2-9- In vitro cytotoxicity assay}

MTT assay was applied for investigation of the cytotoxicity of free DOX, HMCNs-PCH-p-I, DOX-loaded-HMNCs-PCH-p-I（HMCNs-PCH-p-I@D)，calcium-latched-HMNCs-PCH-p-I, and DOX-loaded-calcium-latched-HMCNs-PCH-p-I (calcium-latched-HMCNs-PCH-p-I@D) on HeLa human breast cancer cells. Growing of the cells was performed in DMEM with 5\% fetal bovine serum and $100 \mathrm{mg} / \mathrm{mL}$ penicillin $\mathrm{G}$ and $100 \mathrm{mg} / \mathrm{mL}$ streptomycin at $37{ }^{\circ} \mathrm{C}$ in a humidified $5 \% \mathrm{CO}_{2}$ atmosphere. Then, 96-well plates $\left(1 \times 10^{4}\right.$ cells per well $)$ were applied to seed the cells. The samples were sterilized with UV radiation and transferred to culture wells at different concentrations. The concentration of the samples either as the nanospheres without DOX or DOX-loaded nanospheres (HMCNs-PCH-p-I@D and calcium-latchedHMCNs-PCH-p-I@D) were 60, 30, 15, 7.5, $4 \mu \mathrm{g} / \mathrm{mL}$. Also, the concentrations of DOX either as free DOX or DOX-loaded nanospheres (HMCNs-PCH-p-I@D and calcium-latchedHMCNs-PCH-p-I@D) were 10.73, 5.38, 2.68, 1.8, and $0.63 \mu \mathrm{g} / \mathrm{ml}$ at horizontal axis values of $60,30,15,7.5$, and $4 \mu \mathrm{g} / \mathrm{mL}$ (concentration of the samples), respectively. The cells were washed with PBS solution after $24 \mathrm{~h}$ and $48 \mathrm{~h}$ incubation time. The MTT solution $(100 \mu \mathrm{L}$, $0.5 \mathrm{~g} / \mathrm{L}$ ) was added to each well and the incubation was performed for $4 \mathrm{~h}$. In this step, the 
MTT reagent was reduced to formazan and DMSO was used for dissolving the formazan. The absorbance was measured at $490 \mathrm{~nm}$. All the experiments were performed three times. The cell viability was measured by the following equation:

$$
\text { cell viability } \%=\frac{\text { means of abs, value of treatment sample }}{\text { means of abs, value of control sample }} \times 100
$$

\section{2-10- Cellular uptake studies by fluorescence microscopy}

For determining the cellular uptake of the calcium latched-HMCNs-PCH-p-I@D (DOXloaded nanocarrier), HeLa cancer cells were seeded in 6 -well plate $\left(1 \times 10^{5}\right.$ cells per well). Then, the cell incubation was performed at $37{ }^{\circ} \mathrm{C}$ for $24 \mathrm{~h}$ in a humidified $5 \% \mathrm{CO}_{2}$ atmosphere. Afterward, DOX-loaded nanocarrier was added to the cells at the concentrations of DOX about 10 and $20 \mu \mathrm{g} / \mathrm{mL}$. The treatment was performed for $6 \mathrm{~h}$ and $24 \mathrm{~h}$. At the end, the cells were washed with cold PBS. 4',6-diamidino-2-phenylindole (DAPI) was applied for staining of the cell nucleus and paraformaldehyde was used for fixing. The stained cells were observed by confocal laser scanning microscopy (CLSM, Leica TCS SPE, Germany). The excitation wavelengths for DAPI and DOX were 405 and $480 \mathrm{~nm}$, respectively and the emission fluorescence was recorded at 440-480 $\mathrm{nm}$ and 550-600 nm, respectively.

\section{2-11- Cellular uptake studies by flow cytometry}

HeLa cancer cells were seeded in 6-well plates $\left(1 \times 10^{5}\right.$ cells per well $)$ and incubated at $37^{\circ} \mathrm{C}$ for $24 \mathrm{~h}$ in a humidified $5 \% \mathrm{CO}_{2}$ atmosphere. After that, the free DOX and the calcium latched- HMCNs-PCH-I@D (DOX-loaded nanocarrier) were added at the DOX concentration of 10 and $20 \mu \mathrm{g} / \mathrm{mL}$ and incubation was performed for $3 \mathrm{~h}$. The cells were trypsinized and washed by phosphate buffered saline (PBS; $\mathrm{pH} 7.4$ ) for $5 \mathrm{~min}$. Then, the fluorescence emission was recorded on a flow cytometer (BD FACSCalibur, San Jose, CA, USA) at excitation wavelength of $480 \mathrm{~nm}$ (emission wavelength $590 \mathrm{~nm}$ ). 


\section{Results and discussion}

\subsection{Synthesis and characterization}

In this work, the $\mathrm{pH}$-sensitive nanocarrier based-on hollow mesoporous carbon nanospheres (HMCNs) were prepared by a hydrothermal reaction and a silica etching process for removing silica template. Then, poly(epichlorohydrin) was grown on the surface of nanospheres as an oxygen-rich polymer. The primary amine groups on the surface of HMCNs acted as the initiating sites for the ring-opening polymerization of epicholohydin monomer. The chlorine pendant groups in the oxygen-rich polymer were replaced with imidazole. At the end, by the interaction of calcium ion with imidazole group, a pH-sensitive nanocarrier basedon the coordination bonding (on/off capping or gating system) was prepared (Scheme 1). The nanocarrier was applied for loading and releasing of DOX through the mesopores on its surface. 


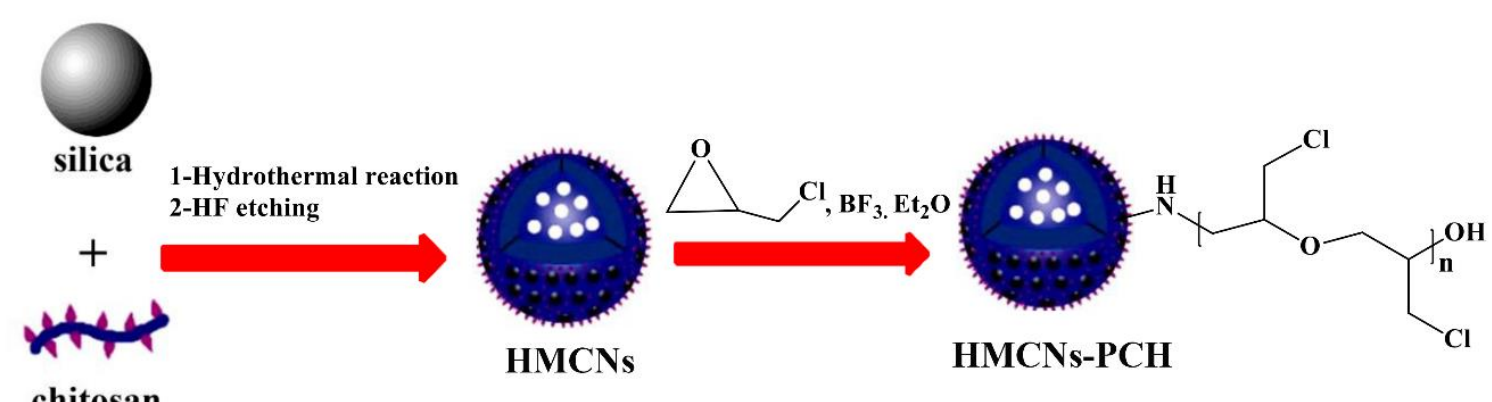

chitosan

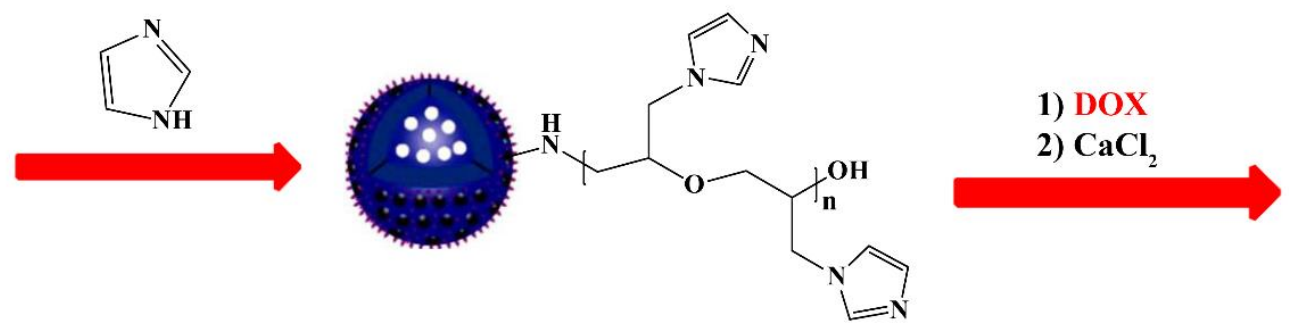

HMCNs-PCH-p-I

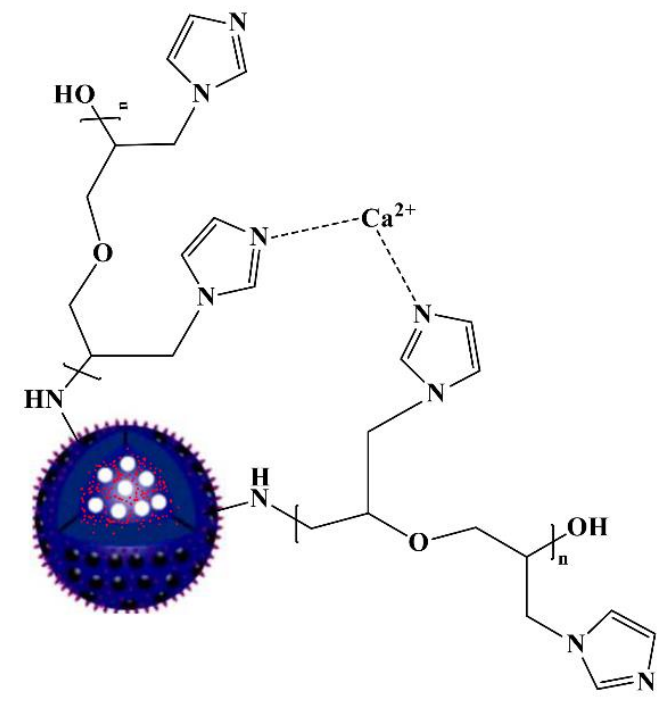

calcium-latched-HMCNs-PCH-p-I@D

Scheme 1. Overall synthesis route of calcium-latched-HMNCs-PCH-p-I nanocarrier

The FT-IR spectra of HMCNs, HMCNs-PCH, and HMCNs-PCH-p-I are shown in the Figure

1. The spectrum of HMCNs shows a peak at $1645 \mathrm{~cm}^{-1}$ attributed to bending vibrations of the primary amine groups. After modification of HMCNs with poly(epichlorohydrin), new peaks appeared at $747 \mathrm{~cm}^{-1}$ and $2800-2900 \mathrm{~cm}^{-1}$ that are related to the stretching vibrations of C$\mathrm{Cl}$ and $\mathrm{CH}_{2}$, respectively. The peak at $1155 \mathrm{~cm}^{-1}$ is corresponded to $\mathrm{C}-\mathrm{N}$ bond formed by the nucleophilic attack of $\mathrm{N}$ atom of imidazole to chlorine. 


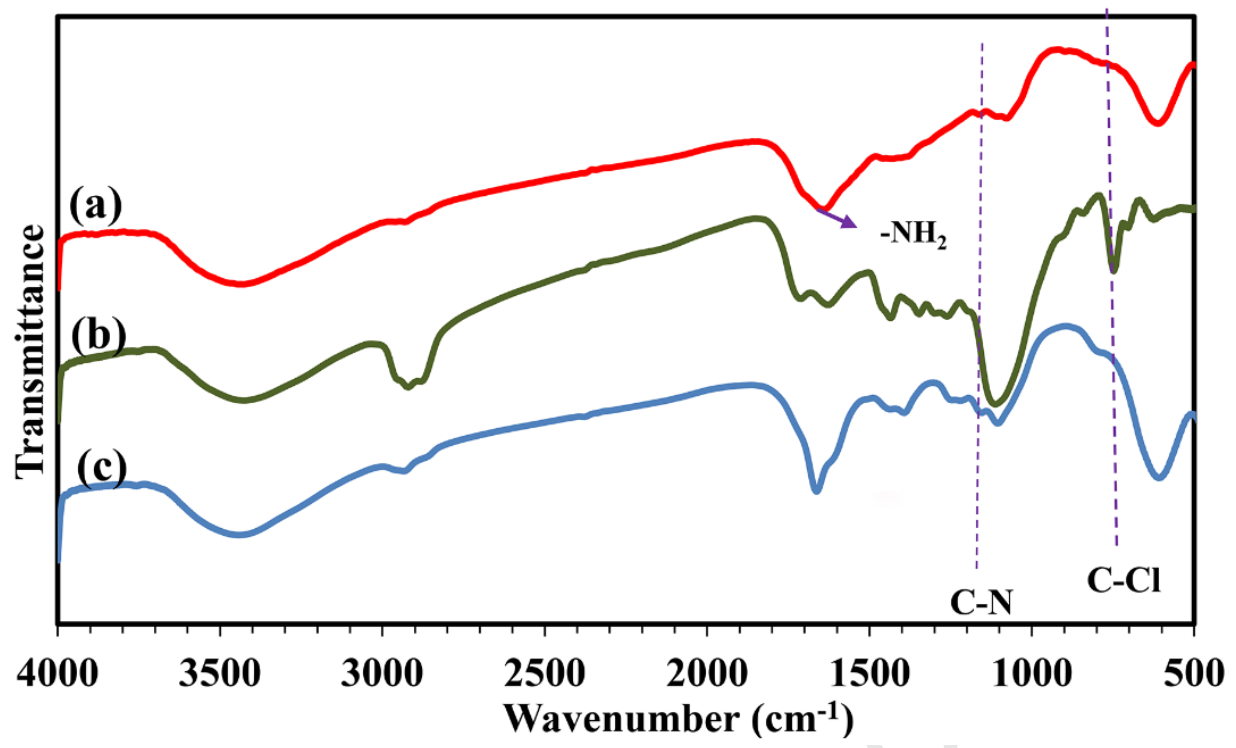

Figure 1. FTIR spectra of (a) HMCNs, (b) HMCNs-PCH, (c) HMCNs-PCH-p-I

UV-Vis and fluorescence spectroscopy were used to confirm for the presence of DOX onto HMCNs-PCH-p-I as are shown in Figure $2 \mathrm{a}$ and Figure $2 \mathrm{~b}$, respectively. The UV-Vis spectrum of HMCNs-PCH-p-I@D indicates a broad peak at $480 \mathrm{~nm}$ which is related to DOX drug. This peak was not observed in the UV-Vis spectrum of HMCNs-PCH-p-I (Figure 2a). Also, the fluorescence spectra confirmed the loading of DOX onto HMCNs-PCH-p-I by the appearance of the peak at 580-620 nm which is due to the presence of DOX (Figure $2 \mathrm{~b}$ ).
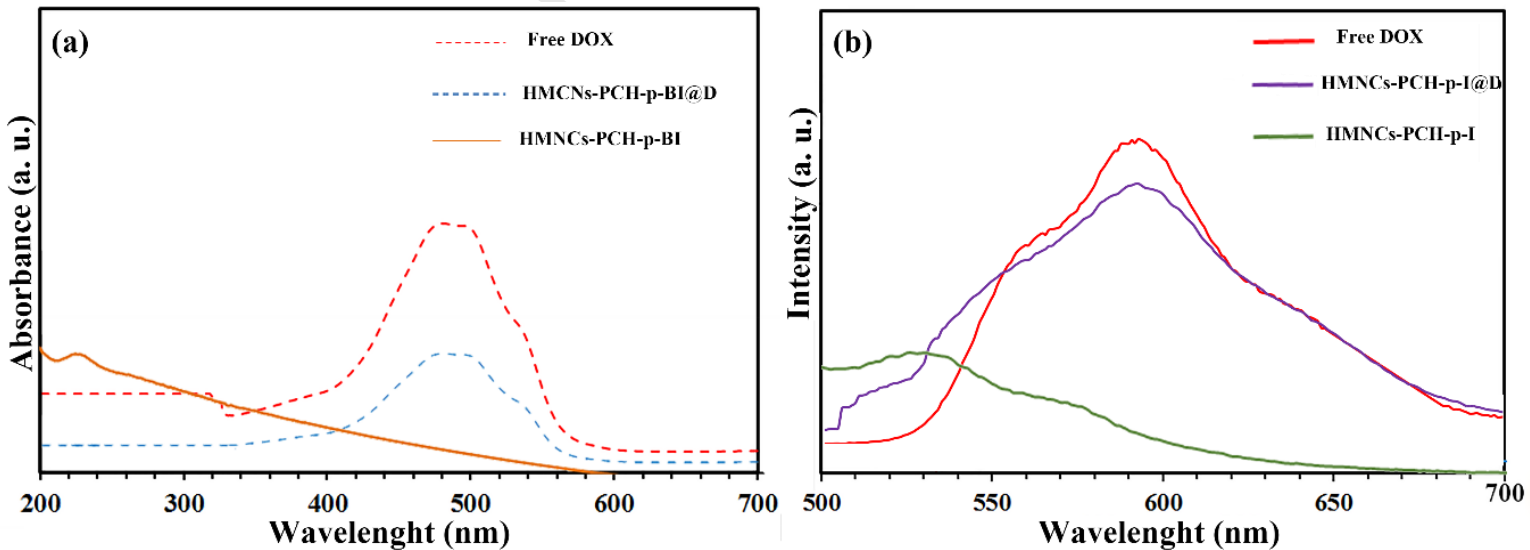

Figure 2. (a) UV-Vis spectra of free DOX, HMCNs-PCH-p-I, and HMCNs-PCH-p-I@D and (b) fluorescence spectra of free DOX, HMCNs-PCH-p-I, and HMCNs-PCH-p-I@D 
The scanning electron microscopy (SEM) image of HMCNs-PCH is displayed in Figure 3. A spherical morphology was observed for HMCNs-PCH nanoparticles. The diameter of HMCNs-PCH nanospheres were found about 40-50 nm. Some aggregation was observed in HMCNs-PCH as a result of the polymer coating on HMCN nanospheres.

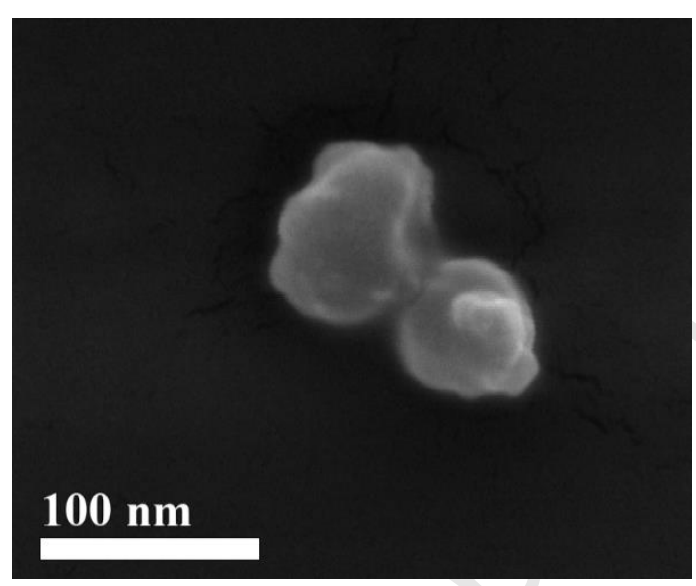

Figure 3. SEM image of HMCNs-PCH nanospheres

Elemental composition of the samples was determined by EDS. The EDS spectrum of HMCNs (Figure 4a) showed the presence of $\mathrm{C}$ and $\mathrm{N}$ atoms and a small peak related to $\mathrm{O}$ atom. The spectra in Figure $4 \mathrm{~b}$ and Figure $4 \mathrm{c}$ revealed the presence of $\mathrm{C}, \mathrm{N}, \mathrm{O}, \mathrm{Cl}$ atoms in HMCNs-PCH and C, N, O atoms in HMCNs-PCH-p-I, respectively. 

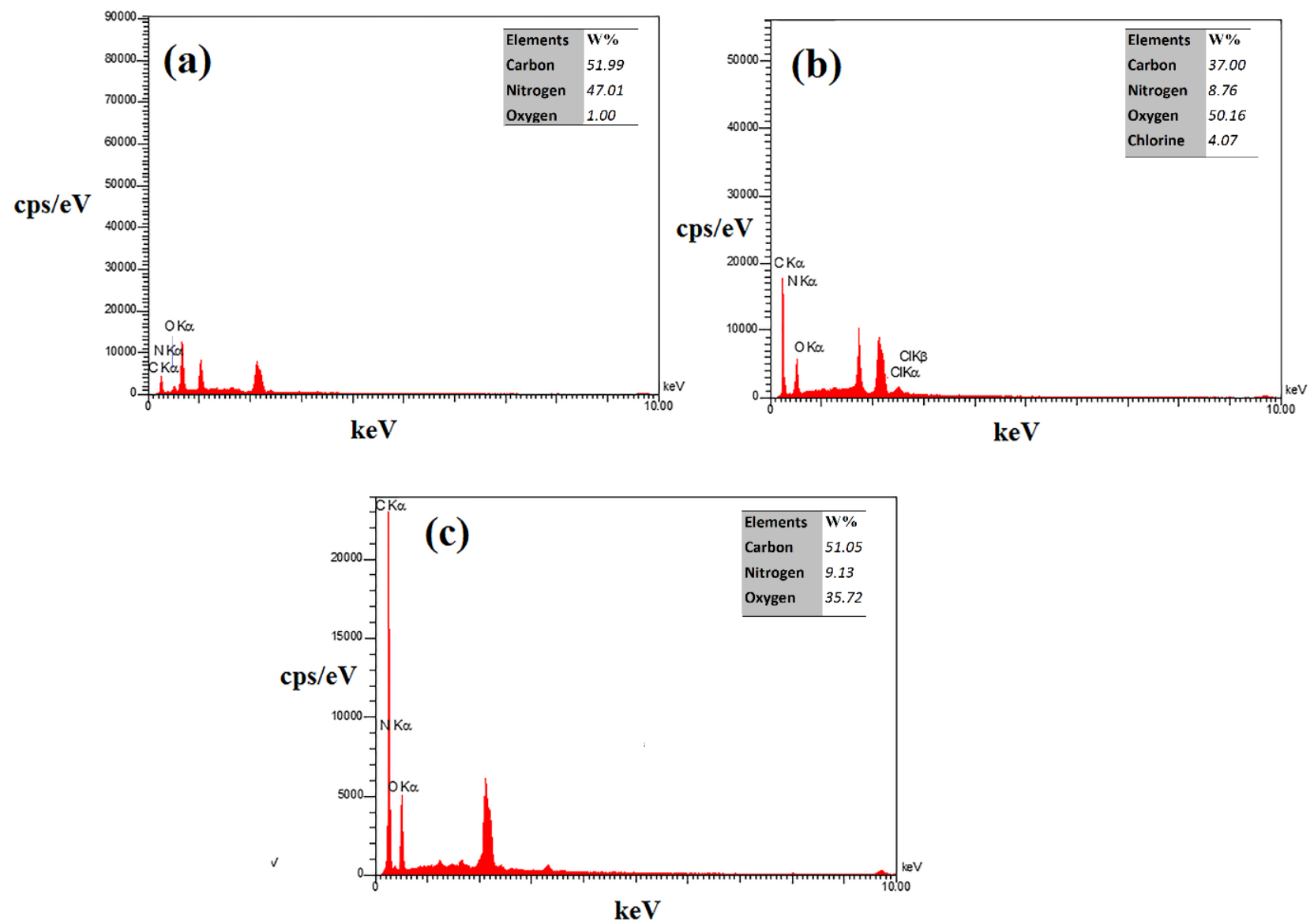

Figure 4. The EDS images of (a) HMCNs, (b) HMCNs-PCH, and (c) HMCNs-PCH-p-I

The morphology of HMCNs-PCH was characterized with high resolution transmission electron microscopy (HRTEM). The TEM images indicate that HMCNs-PCH have a spherical morphology. The diameter of HMCNs-PCH nanospheres was determined about 50 $\mathrm{nm}$ which is in agreement with the value already found by SEM images.
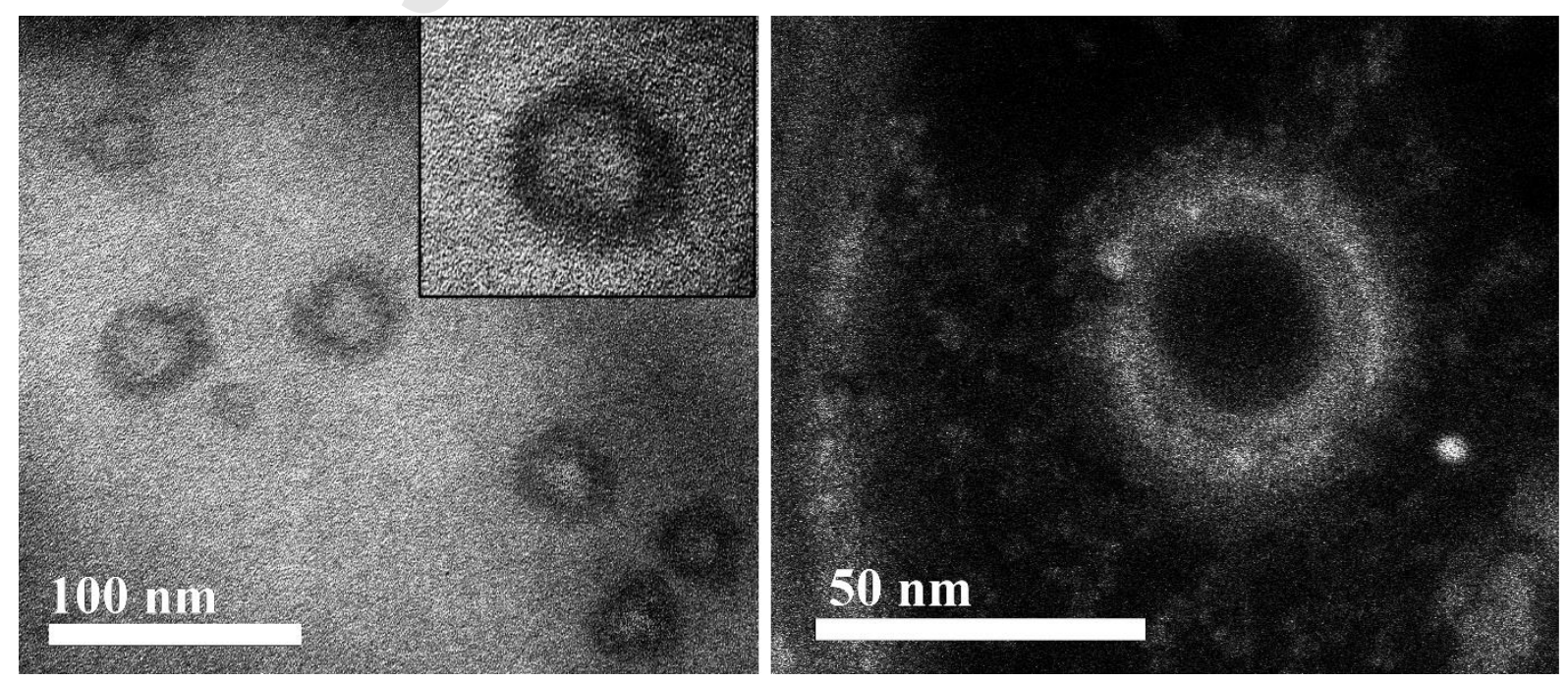
Figure 5. Bright field and dark field TEM images of the HMCNs-PCH.

The thermogravimetric (TGA) curves of HMCNs and HMCNs-PCH are shown in Figure 6a and Figure $6 \mathrm{~b}$, respectively. The weight loss at the range of $30-120{ }^{\circ} \mathrm{C}$ is because of the evaporation of volatile solvents and water molecules[67]. In figure 6a, the gradual weight loss of $\sim 3 \%$ at $600{ }^{\circ} \mathrm{C}$ can be attributed to the decomposition of amine groups attached onto the surface of HMCNs. The low weight loss indicates that HMCNs prepared by hydrothermal reaction have high thermal stability. In the TGA curve of HMCNs-PCH, a weight loss was observed at $200-500{ }^{\circ} \mathrm{C}$ which is related to the thermal decomposition of poly(epichlorohydrin). The loading content of poly(epichlorohydrin) was calculated about $8 \%$.

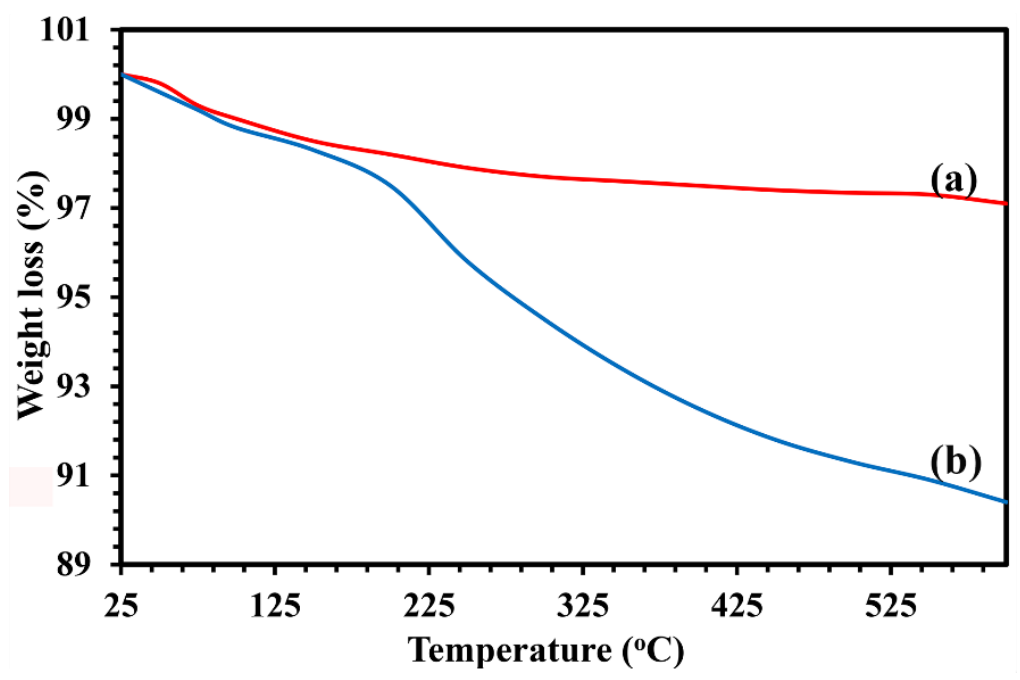

Figure 6. TGA curves of (a) HMCNs, and (b) HMCNs-PCH

Dynamic light scattering (DLS) analysis is a method for determination of size and size distribution of the particles in solution[70]. The DLS of HMCNs and HMCNs-PCH indicated highly dispersed nanoparticles with diameters of $\sim 80 \mathrm{~nm}$ and $93 \mathrm{~nm}$, respectively. Because of the swelling of nanoparticles in water, the diameter of HMCNs-PCH determined by DLS was higher than that observed by TEM analysis. The final nanocarrier also showed well dispersion in PBS and culture medium containing 10\% FBS after even $72 \mathrm{~h}$. 


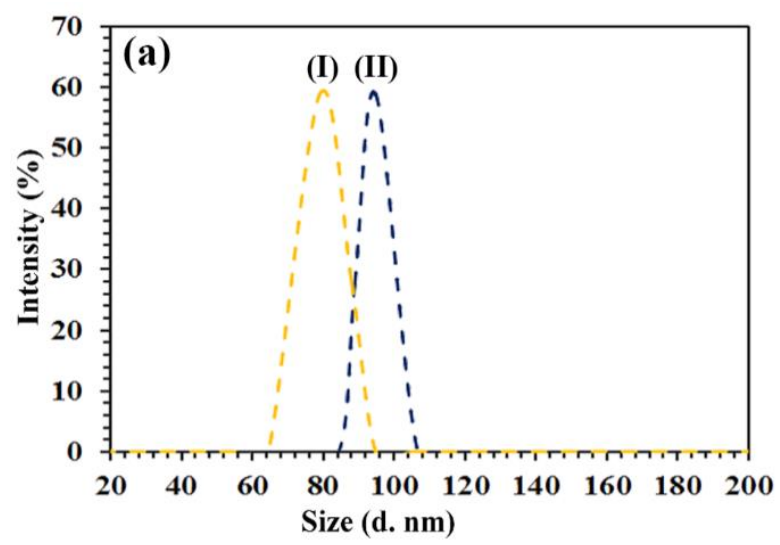

(b)

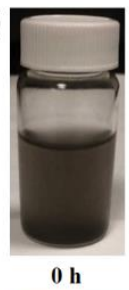

(c)

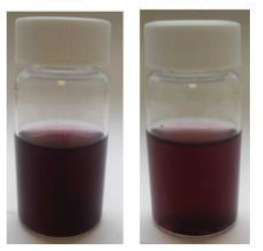

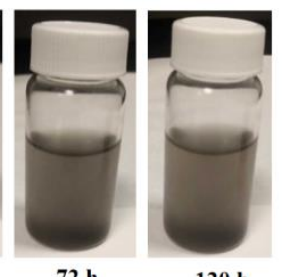

$72 \mathrm{~h}$

$120 \mathrm{~h}$
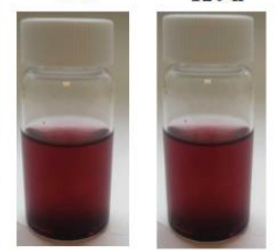

Figure 7. (a) DLS curves of (I) HMCNs and (II) HMCNs-PCH in DI water and dispersion of calcium-latched HMCNs-PCH-p-I at (a) PBS and (b) DMEM high glucose containing 10\% FBS.

Zeta potential analysis determines the attraction, repulsion, and stabilization of the particles [71]. A higher zeta potential value (positive or negative) means a greater stability of the particles against aggregation, but a lower value of zeta potential means that attraction exceeds the repulsion, and aggregation can be happened[72]. The zeta-potential results of the samples at the concentration of $0.1 \% \mathrm{w} / \mathrm{w}$ at $\mathrm{pH}=7$ in deionized water are indicated in Figure 8 . The zeta potential value of silica nanoparticles was $-28.90 \mathrm{mV}$. This negative value is because of the presence of hydroxyl groups on the surface of silica nanoparticles. After the hydrothermal reaction, the zeta potential value increased to $14.40 \mathrm{mV}$ confirming the successful formation of HMCNs. This positive value of zeta potential is related to the primary amine groups on the surface of HMCNs. The zeta potential value of $\mathrm{HMCNs}-\mathrm{PCH}$ was found $-2.30 \mathrm{mV}$ indicating the attachment of poly(epichlorohydrin). After nucleophilic substitution with imidazole, the zeta potential value changed from $-2.30 \mathrm{mV}$ to $+6.90 \mathrm{mV}$ which is because of imidazole groups. The zeta-potential of DOX-loaded-HMCNs-PCH-p-I (HMCNs-PCH-p-I@D) was measured as about $+13.4 \mathrm{mV}$. These results indicate that the loading of DOX increased the zeta potential value of HMCNs-PCH-p-I. 


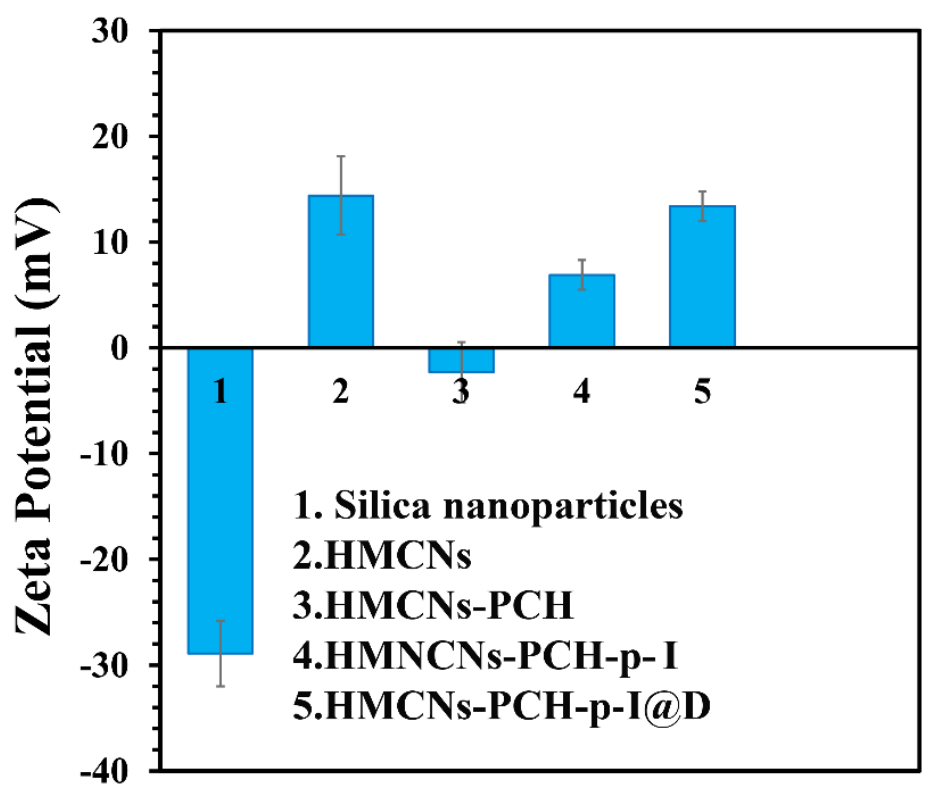

Figure 8. Zeta potential values of the samples in DI water

Brunauer-Emmett-Teller (BET) and Barrett-Joyner-Halenda (BJH) analyses are applied for determining the specific surface area, pore size distribution and pore volume. According to the IUPAC categories, the structure of porous materials is classified to three types based-on the average dimensions of pores including micropores (less than $2 \mathrm{~nm}$ ), mesopores (between 2 to $50 \mathrm{~nm}$ ), and macropores (more than $50 \mathrm{~nm}$ )[73-75]. Figure 9 indicates the $\mathrm{N}_{2}$ adsorptiondesorption isotherm (Figure 9a) and pore size distribution (Figure 9b) of HMCNs at 77 K. A hysteresis loop is clear at medium and high pressure which indicates type IV isotherm[74]. The surface area and pore size were calculated about $162 \mathrm{~m}^{2} / \mathrm{g}, 6.17 \mathrm{~nm}$, respectively. 

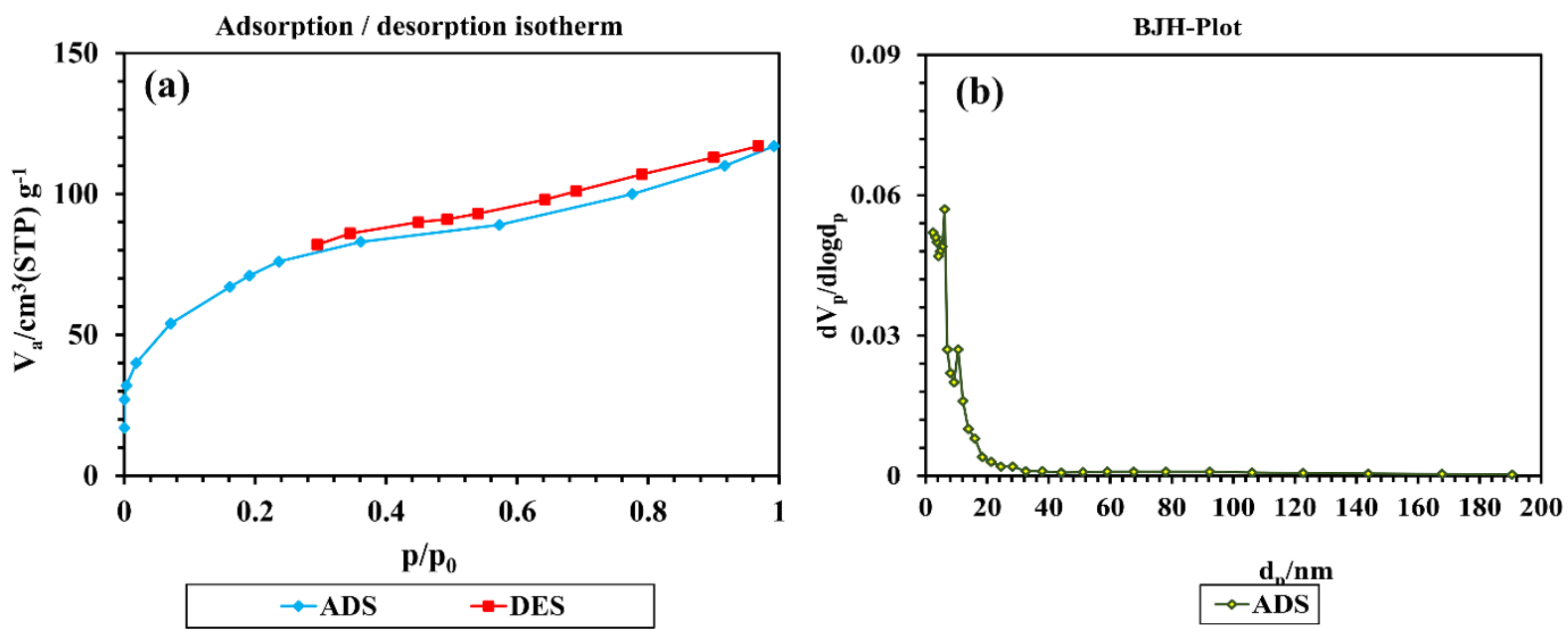

Figure 9. (a) $\mathrm{N}_{2}$ adsorption-desorption isotherms and (b) pore size distribution of HMCNs

\subsection{Drug loading}

The highest loadings of DOX into the nanocarrier were obtained by mixing several concentrations of DOX and HMCNs-PCH-p-I. For this purpose, DOX-loaded HMCNs-PCHp-I nanospheres with different concentration of DOX were prepared. Each experiment was performed in triplicate. The drug loading capacity (DLC) and drug loading efficiency (DLE) were measured by Eq. 1 and Eq. 2, respectively:

$$
\begin{aligned}
& E q .1 \quad D L C\left(\frac{m g}{g}\right)=\frac{M_{I D}-M_{R D}}{M_{N C}} \\
& E q .2 \quad D L E(\%)=\frac{M_{I D}-M_{R D}}{M_{I D}} \times 100
\end{aligned}
$$

Where, $\mathrm{M}_{\mathrm{ID}}$ is the initial drug mass, $\mathrm{M}_{\mathrm{RD}}$ is the residual drug mass in the supernatant solutions, and $M_{\mathrm{NC}}$ is the nanocarrier mass. Figure 10 indicates DLC and DLE curves. The highest DOX capacity into calcium-latched-HMCNs-PCH-p-I was calculated $180 \mathrm{mg} / \mathrm{g}$ and in this amount, approximately $64 \%$ of DOX was adsorbed by nanocarrier. It should be noted that some of DOX molecules are released into the solution during the calcium modification of 
the surface and the values of DLC and DLE are calculated based on the total release of DOX in all steps.

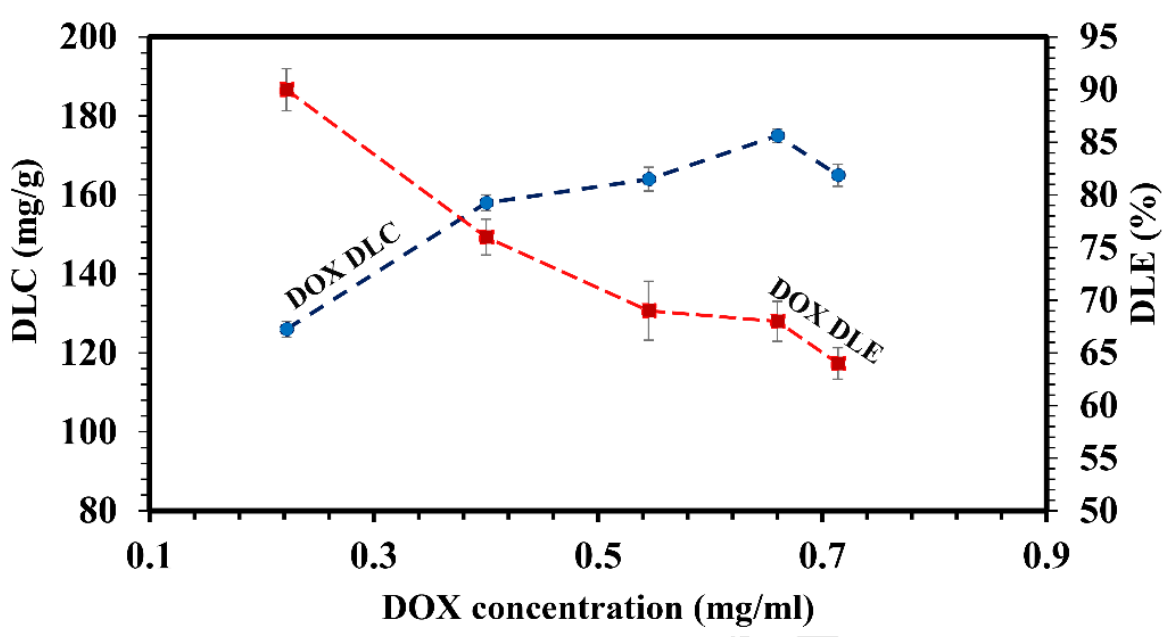

Figure 10. DLC and DLE curves for the DOX loaded- HMCNs-PCH-p-I

\section{3-3- Drug release}

The release behavior of DOX from HMCNs@D, HMCNs-PCH-p-I@D, and calcium latchedHMCNs-PCH-p-I@D was investigated by a dialysis method at $37{ }^{\circ} \mathrm{C}$ in PBS buffer solution at $\mathrm{pH}=5.0$ and $\mathrm{pH}=7.4$. The release profile of DOX from HMCNs@D, HMCNs-PCH-p$\mathrm{I} @ \mathrm{D}$, and calcium-latched-HMNCs-PCH-p-I@D at $\mathrm{pH}=5.0$ and $\mathrm{pH}=7.4$ is indicated in Figure 11a, Figure 11b, and Figure 11c, respectively. HMCNs showed an immediate release of $\mathrm{DOX}$ at $\mathrm{pH}=5.0$ and $\mathrm{pH}=7.4$. Also, the nanospheres showed a similar release behavior of DOX in both $\mathrm{pH}=5$ and $\mathrm{pH}=7.4$ because the HMCNs do not exhibit a $\mathrm{pH}$-dependent release behavior. The release amount of DOX from HMCNs was about 93\% at $\mathrm{pH}=5.0$ and about $89 \%$ at $\mathrm{pH}=7.4$ after $92 \mathrm{~h}$. Also, HMCNs-PCH-p-I nanospheres indicated a release almost independent of $\mathrm{pH}$. The pendant imidazole groups can be protonated in acidic $\mathrm{pH}$ and increase the DOX release in $\mathrm{pH}=5.0$. Calcium-latched-HMCNs-PCH-p-I@D indicated a controlled and $\mathrm{pH}$-dependent release behavior of DOX. As shown, the release amount of DOX from Calcium-latched-HMCNs-PCH-p-I was about $43 \%$ at $\mathrm{pH}=5.0$ and $24 \%$ at $\mathrm{pH}=$ 7.4 after $20 \mathrm{~h}$. The DOX release increased with increasing time (after $92 \mathrm{~h}$ ) and reached to 
$87 \%$ and $33 \%$ at $\mathrm{pH}=5.0$ and at $\mathrm{pH}=7.4$, respectively. These results confirm that the release of DOX from calcium-latched-HMCNs-PCH-p-I is $\mathrm{pH}$-sensitive which is attributed to the coordination bonding between imidazole groups and calcium ions. Figure 11d shows the release behavior of calcium ions. The release amount of calcium ions from calcium-latchedHMCNs-PCH-p-I was about $25 \mu \mathrm{g} / \mathrm{mL}$ at $\mathrm{pH}=5.0$ and $12 \mu \mathrm{g} / \mathrm{mL}$ at $\mathrm{pH}=7.4$ after $92 \mathrm{~h}$. So, a small amount of calcium is released at the same time of DOX.
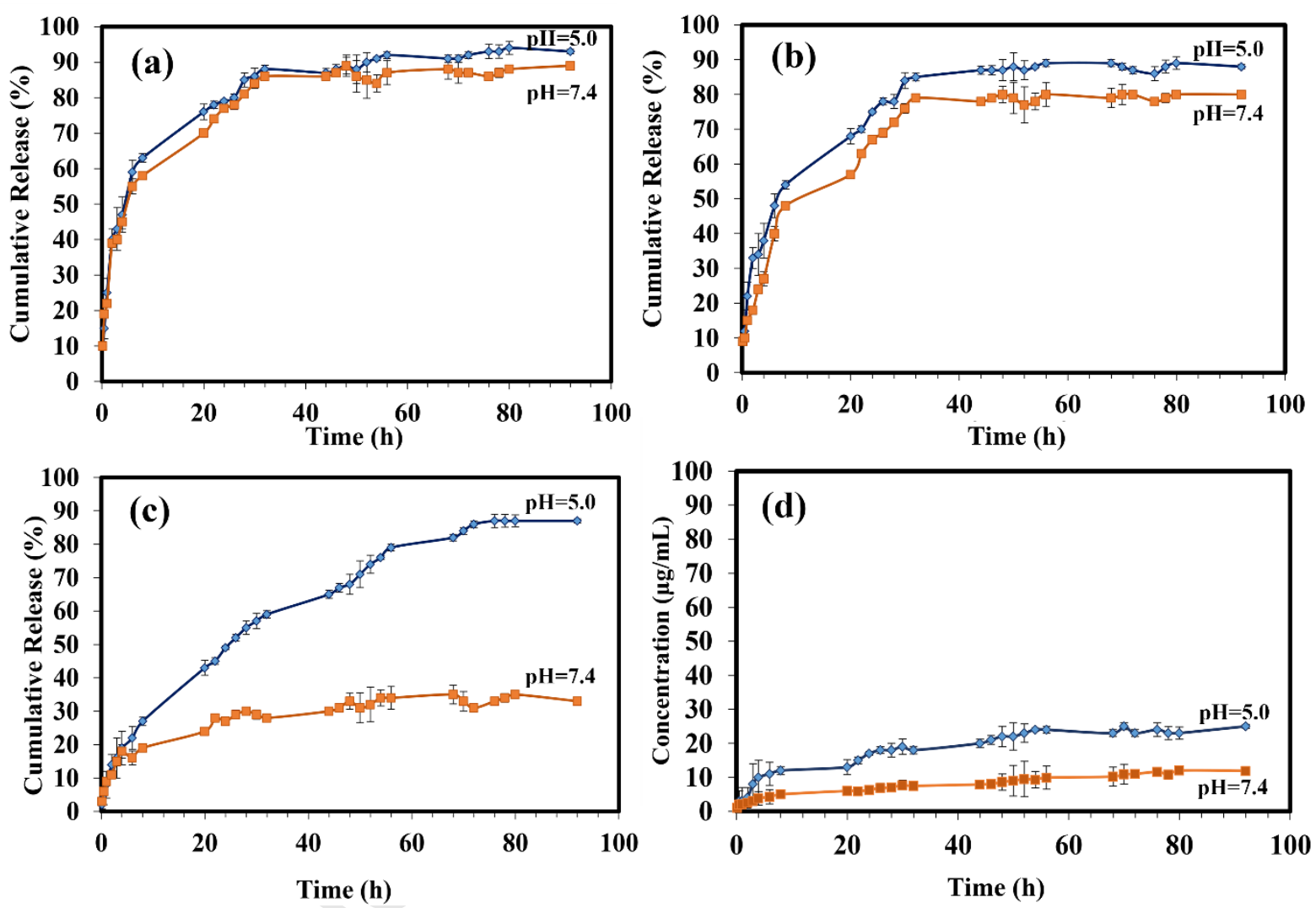

Figure 11. The release behavior of DOX from (a) HMCNs, (b) HMCNs-PCH-p-I, (c) calcium-latched-HMCNs-PCH-p-I, and the release behavior of $\mathrm{Ca}^{2+}$ from (d) at pH=7.4 and

$$
\mathrm{pH}=5 \text { at } 37^{\circ} \mathrm{C} \text {. }
$$

\section{3-4- MTT assay}

MTT assay was performed through the colorimetric analysis based on the reduction of tetrazolium salt to a red-colored formazan. The amount of formazan resulted in the reduction is directly related to the number of viable cells $[76,77]$. The cytotoxicity of free DOX, 
HMCNs-PCH-p-I, DOX-loaded-HMCNs-PCH-p-I (HMCNs-PCH-p-I@D), calcium-latchedHMCNs-PCH-p-I， and DOX-loaded-calcium-latched-HMCNs-PCH-p-I (calcium-latchedHMCNs-PCH-p-I@D) was investigated by MTT assay. The concentrations of DOX either as free DOX or the DOX-loaded nanospheres (HMCNs-PCH-p-I@D and calcium-latchedHMCNs-PCH-p-I@D) were 10.73, 5.38, 2.68, 1.8, and $0.63 \mu \mathrm{g} / \mathrm{mL}$ at horizontal axis values of $60,30,15,7.5$, and $4 \mu \mathrm{g} / \mathrm{ml}$ (concentration of the samples), respectively. The incubation times were $24 \mathrm{~h}$ and $48 \mathrm{~h}$. As is shown in Figure 12, by increasing of incubation time and concentration of the samples, the cell viability decreased and cytotoxicity against HeLa cells increased. The cytotoxicity of both HMCNs-PCH-p-I@D and calcium-latched-HMCNs-PCHp-I@D is lower than that of free DOX because of the lower amount of released DOX from the nanospheres than the amount of free DOX. The DOX-loaded nanospheres is endocytosed to diffuse into the cells and DOX molecules are released slowly but free DOX can diffuse into cells easily and rapidly[78]. Also, calcium-latched-HMCNs-PCH-p-I@D showed a little more cytotoxicity compared to HMCNs-PCH-p-I@D because of the presence of the calcium ions. As can be seen, the nanospheres without DOX (HMCNs-PCH-p-I and calcium-latchedHMCNs-PCH-p-I) showed low cytotoxicity even by increasing incubation time and the concentration of the samples.
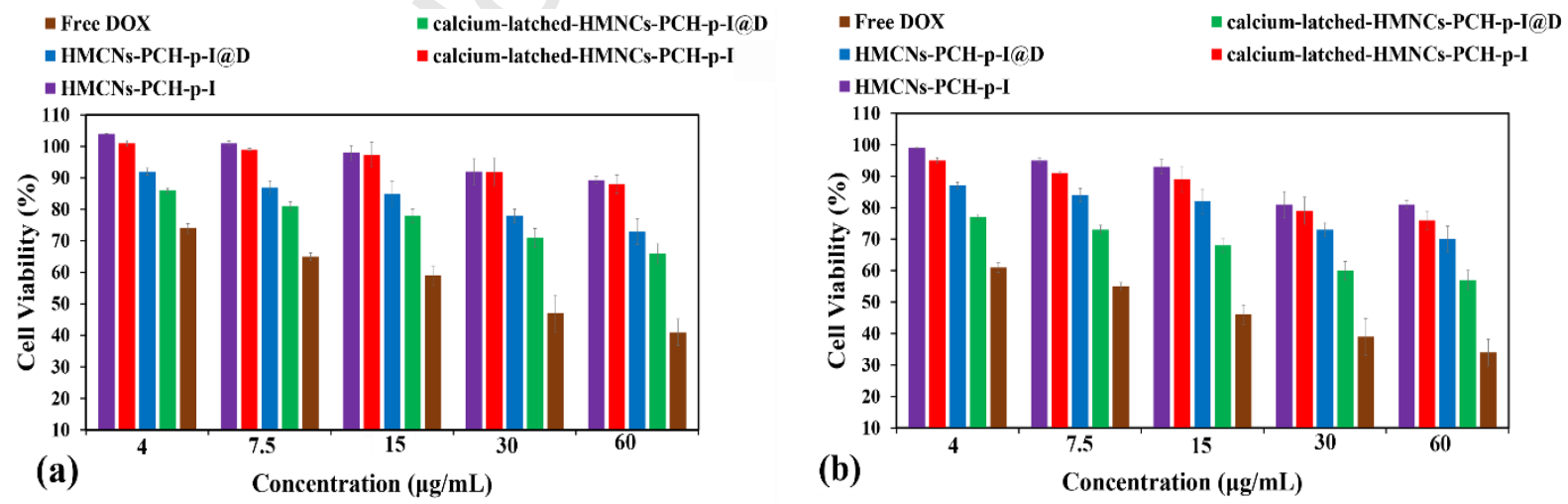
Figure 12. Cytotoxicity study of the free DOX, HMCNs-PCH-p-I, HMCNs-PCH-p-I@D, calcium-latched-HMCNs-PCH-p-I, and calcium-latched-HMCNs-PCH-p-I@ D toward HeLa cancer cells after (a) $24 \mathrm{~h}$ and (b) $48 \mathrm{~h}$ incubation times at $37{ }^{\circ} \mathrm{C}$.

\section{3-5- Cellular uptake investigations by flow cytometry}

An appropriate method to investigate the cellular internalization of the labeled molecules is flow cytometry technique that measures the florescence intensity. For evaluation of the cellular uptake of DOX, florescence intensity of DOX in free DOX and the DOX-loaded nanocarrier (calcium-latched-HMCNs-PCH-p-I@ D) was determined at incubation time of $3 \mathrm{~h}$ and the DOX concentrations of 10 and $20 \mu \mathrm{g} / \mathrm{mL}$. After incubation, the cells were washed several times with PBS buffer to remove calcium-latched-HMCNs-PCH-p-I adsorbed onto the cells. A self-fluorescence is observed by cells without any incubation with the samples used as negative control. Figure 14 shows the flow cytometry histograms of DOX fluorescence at the concentration of 10 and $20 \mu \mathrm{g} / \mathrm{mL}$. As shown, the fluorescence intensity of DOX was enhanced by increasing DOX concentration. Also, free DOX showed a higher cellular uptake than calcium-latched-HMCNs-PCH-p-I@D after $3 \mathrm{~h}$ which is because of difference in the mechanism of cell internalization of free DOX and the DOX-loaded nanocarrier. Free DOX diffuses into the cells rapidly but DOX-loaded nanocarrier is internalized by the endocytosis process[79, 80].

(a)

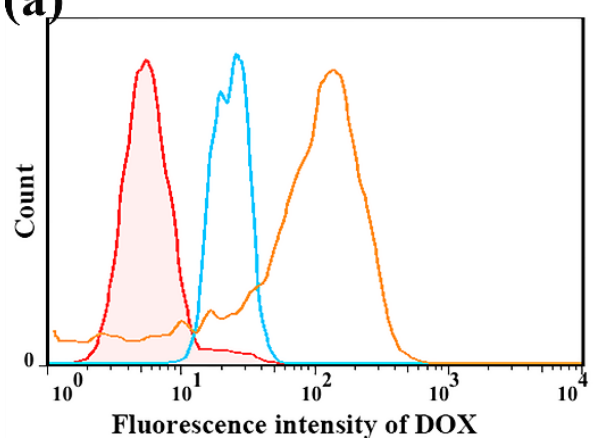

(b)

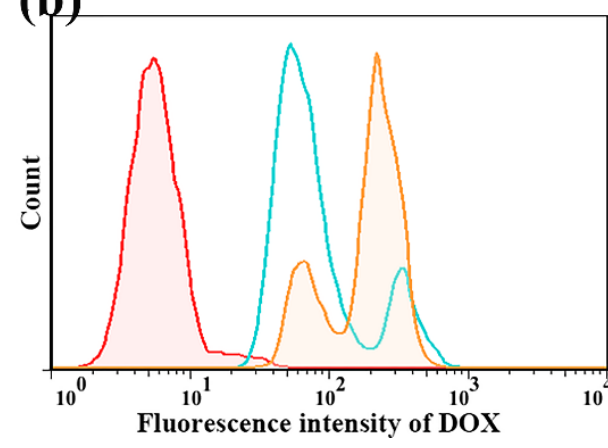

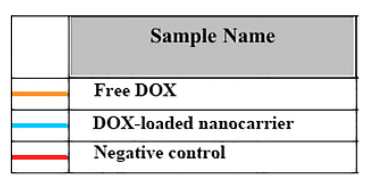


Figure 13. Flow cytometry of HeLa cells treated with free DOX and the DOX-loaded nanocarrier (calcium-latched-HMCNs-PCH-p-I@D) at (a) $10 \mu \mathrm{g} / \mathrm{mL}$ and (b) $20 \mu \mathrm{g} / \mathrm{mL}$ at $3 \mathrm{~h}$

\section{3-6- Cellular uptake studies by fluorescence microscopy}

Confocal laser scanning microscope (CLSM) was applied for investigation of the cellular uptake and localization of the samples in HeLa cancer cells (Figure 14). DAPI (4',6diamidino-2-phenylindole) was used for labeling of cancer cells nuclei. The concentrations of DOX in the calcium-latched-HMCNs-PCH-p-I@D were 10 and $20 \mu \mathrm{g} / \mathrm{mL}$ and the incubation times were $6 \mathrm{~h}$ and $24 \mathrm{~h}$. By increasing the incubation time from $6 \mathrm{~h}$ to $24 \mathrm{~h}$, the cellular uptake of the calcium-latched-HMCNs-PCH-p-I@D was improved and the fluorescence intensity was increased. The merged images of DAPI and DOX indicated the cellular internalization of the calcium-latched-HMCNs-PCH-p-I@D within HeLa cells after incubation times. 

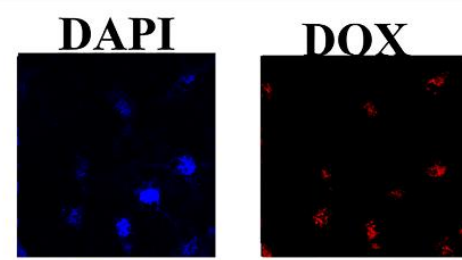

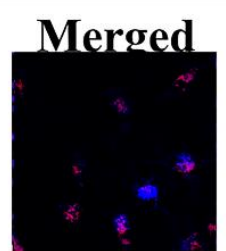

Incubation time

$6 \mathrm{~h}$

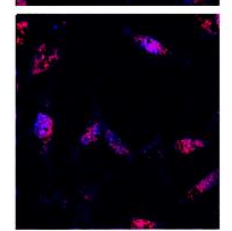

$6 \mathrm{~h}$
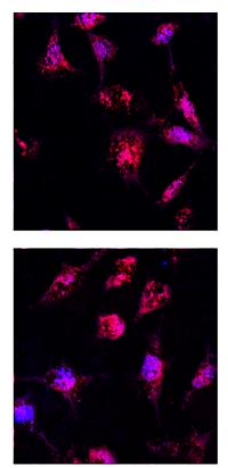

$24 \mathrm{~h}$

$24 \mathrm{~h}$

\section{Conentration of DOX}

$10 \mu \mathrm{g} / \mathrm{ml}$

$20 \mu \mathrm{g} / \mathrm{ml}$

$10 \mu \mathrm{g} / \mathrm{ml}$
$20 \mu \mathrm{g} / \mathrm{ml}$

Figure 14. CLSM images of calcium-latched-HMCNs-PCH-p-I@D on the HeLa cells incubated for $6 \mathrm{~h}$ and $24 \mathrm{~h}$ at the DOX concentration of 10 and $20 \mu \mathrm{g} / \mathrm{mL}$ at $37^{\circ} \mathrm{C}$.

\section{4- Conclusion}

Herein, we synthesized a novel $\mathrm{pH}$-sensitive nanocarrier based-on hollow mesoporous carbon nanospheres (HMCNs) modified with an oxygen-rich polymer (poly(epichlorohydrin)(PCH)) containing pendant imidazole groups. The coordination bonds were formed between the pendant imidazole groups and calcium ions and calcium-latched-HMCNs-PCH-p-I was prepared as the final nanocarrier. The prepared nanocarrier has high hydrophilicity and low toxicity. DOX as a model of hydrophilic anticancer drug was loaded onto the nanocarrier. The release mechanism of DOX is based-on the cleavage of $\mathrm{pH}$-sensitive coordination bonds. The nanocarrier exhibited low toxicity because of the surface modification with the oxygen- 
rich polymer. The cellular uptake of the nanocarrier for HeLa cancer cells was confirmed by CLSM images and flow cytometry.

\section{Acknowledgments}

The authors are grateful for the financial support from the Sharif University of Technology grant program (G940607). We are grateful to Mr. Mojtaba Nazari to English edit of the manuscript. 

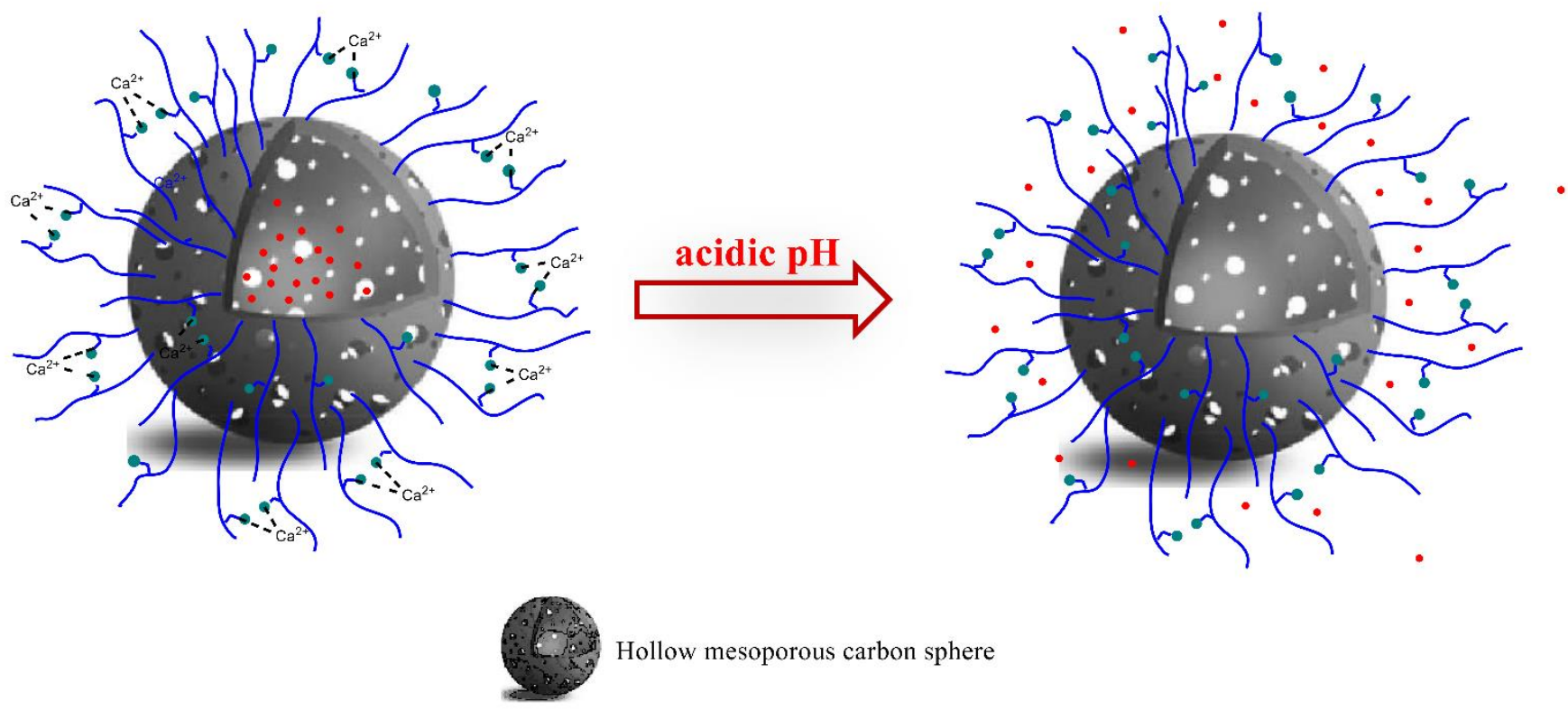

- Doxorubicin

- 1H-benzimidazole

Poly(epichlorohydrin) chains

\section{Graphic abstract}




\section{References}

[1] K. Park, Journal of Controlled Release, 190 (2014) 3-8.

[2] A. Pourjavadi, S.S. Amin, S.H. Hosseini, Industrial \& Engineering Chemistry Research, 57 (2018) 822-832.

[3] A. Pourjavadi, S. Asgari, S.H. Hosseini, M. Akhlaghi, Langmuir, 34 (2018) 15304-15318.

[4] A. Pourjavadi, M. Kohestanian, M. Shirzad, Colloids and Surfaces B: Biointerfaces, 174 (2019) 153160.

[5] S.H. Hosseini, S. Alipour, N. Zohreh, Langmuir, 34 (2018) 13735-13744.

[6] Q. Lu, M. Yi, M. Zhang, Z. Shi, S. Zhang, Langmuir, 35 (2018) 504-512.

[7] Y. Yang, K. Achazi, Y. Jia, Q. Wei, R. Haag, J. Li, Langmuir, 32 (2016) 12453-12460.

[8] A. Jamburidze, A. Huerre, D. Baresch, V. Poulichet, M. De Corato, V. Garbin, Langmuir, (2019).

[9] J. Dong, Y. Zhao, H. Chen, L. Liu, W. Zhang, B. Sun, M. Yang, Y. Wang, L. Dong, New Journal of Chemistry, 42 (2018) 14263-14270.

[10] G. Verma, N.G. Shetake, K. Barick, B. Pandey, P. Hassan, K. Priyadarsini, New Journal of Chemistry, 42 (2018) 6283-6292.

[11] Z.-Q. Feng, K. Yan, J. Li, X. Xu, T. Yuan, T. Wang, J. Zheng, Materials Science and Engineering: C, 104 (2019) 110001.

[12] L. Etchenausia, E. Villar-Alvarez, J. Forcada, M. Save, P. Taboada, Materials Science and Engineering: C, (2019) 109871.

[13] Y.-g. Bi, Z.-t. Lin, S.-t. Deng, Materials Science and Engineering: C, 100 (2019) 576-583.

[14] C. Liang, Z. Li, S. Dai, Angewandte Chemie International Edition, 47 (2008) 3696-3717.

[15] Y. Meng, D. Gu, F. Zhang, Y. Shi, H. Yang, Z. Li, C. Yu, B. Tu, D. Zhao, Angewandte Chemie International Edition, 44 (2005) 7053-7059.

[16] Y. Meng, D. Gu, F. Zhang, Y. Shi, L. Cheng, D. Feng, Z. Wu, Z. Chen, Y. Wan, A. Stein, Chemistry of materials, 18 (2006) 4447-4464.

[17] S. Zhu, C. Chen, Z. Chen, X. Liu, Y. Li, Y. Shi, D. Zhang, Materials Chemistry and Physics, 126 (2011) 357-363.

[18] M. Wang, J. Han, G. Yuan, R. Guo, New Journal of Chemistry, (2019).

[19] J. Zhang, L. Liu, G. Qian, Z. Zhou, K. Xiao, S. Cheng, Y. Wang, Y. Liu, Y. Feng, New Journal of Chemistry, 43 (2019) 2171-2178.

[20] R.-L. Liu, Z.-Q. Zhang, W.-H. Jing, L. Wang, Z.-M. Luo, R.-M. Chang, A.-G. Zeng, W. Du, C. Chang, Q. Fu, Materials Science and Engineering: C, 62 (2016) 605-613.

[21] B. Haghighi, B. Karimi, M. Tavahodi, H. Behzadneia, Materials Science and Engineering: C, 52 (2015) 219-224.

[22] S. Zhang, X. Qian, L. Zhang, W. Peng, Y. Chen, Nanoscale, 7 (2015) 7632-7643.

[23] Y. Zhang, L. Han, L.-L. Hu, Y.-Q. Chang, R.-H. He, M.-L. Chen, Y. Shu, J.-H. Wang, Journal of Materials Chemistry B, 4 (2016) 5178-5184.

[24] L. Zhang, W. Zheng, R. Tang, N. Wang, W. Zhang, X. Jiang, Biomaterials, 104 (2016) 269-278.

[25] X. Zhao, P. Liu, Molecular pharmaceutics, 11 (2014) 1599-1610.

[26] L. Zhang, P. Wang, W. Zheng, X. Jiang, Journal of Materials Chemistry B, 5 (2017) 6601-6607.

[27] X. Wang, Y. Lin, X. Li, D. Wang, D. Di, Q. Zhao, S. Wang, Journal of colloid and interface science, 507 (2017) 410-420.

[28] Y. Zhang, W. Zhu, H. Zhang, J. Han, L. Zhang, Q. Lin, F. Ai, International journal of pharmaceutics, 532 (2017) 384-392.

[29] L. Zhang, M. Yao, W. Yan, X. Liu, B. Jiang, Z. Qian, Y. Gao, X.-j. Lu, X. Chen, Q.-I. Wang, International journal of nanomedicine, 12 (2017) 6759.

[30] L. Zhang, X. Yang, Y. Li, W. Zheng, X. Jiang, Carbon, 121 (2017) 79-89.

[31] S. Mohapatra, S.R. Rout, R.K. Das, S. Nayak, S.K. Ghosh, Langmuir, 32 (2016) 1611-1620.

[32] X. Wei, L. Zhang, S. Li, X. Chen, M. Zhang, C. Wang, T. Wang, L. Li, New Journal of Chemistry, 42 (2018) 923-929. 
[33] L. Chen, J. Zheng, J. Du, S. Yu, Y. Yang, X. Liu, Materials Science and Engineering: C, 104 (2019) 109939.

[34] X. Li, C. Liu, S. Wang, J. Jiao, D. Di, T. Jiang, Q. Zhao, S. Wang, Materials Science and Engineering: C, 71 (2017) 594-603.

[35] L. Zhang, Z. Lu, Y. Bai, T. Wang, Z. Wang, J. Chen, Y. Ding, F. Yang, Z. Xiao, S. Ju, Journal of Materials Chemistry B, 1 (2013) 1289-1295.

[36] C. Yang, W. Guo, L. Cui, N. An, T. Zhang, H. Lin, F. Qu, Langmuir, 30 (2014) 9819-9827.

[37] X. Li, C. Xie, H. Xia, Z. Wang, Langmuir, 34 (2018) 9974-9981.

[38] A. Lajevardi, M.H. Sadr, M.T. Yaraki, A. Badiei, M. Armaghan, New Journal of Chemistry, 42 (2018) 9690-9701.

[39] X. Liu, A.L. Miller II, B.E. Waletzki, T.K. Mamo, M.J. Yaszemski, L. Lu, New Journal of Chemistry, 39 (2015) 8840-8847.

[40] O. Lv, Y. Tao, Y. Qin, C. Chen, Y. Pan, L. Deng, L. Liu, Y. Kong, Materials Science and Engineering: C, 67 (2016) 478-485.

[41] B. Zhang, X. Yang, Y. Wang, G. Zhai, Materials Science and Engineering: C, 75 (2017) 198-206.

[42] C. Théron, A. Gallud, C. Carcel, M. Gary-Bobo, M. Maynadier, M. Garcia, J. Lu, F. Tamanoi, J.I. Zink, M. Wong Chi Man, Chemistry-A European Journal, 20 (2014) 9372-9380.

[43] A. Pourjavadi, Z.M. Tehrani, International Journal of Polymeric Materials and Polymeric Biomaterials, 66 (2017) 336-348.

[44] K.-N. Yang, C.-Q. Zhang, W. Wang, P.C. Wang, J.-P. Zhou, X.-J. Liang, Cancer biology \& medicine, 11 (2014) 34.

[45] D. Tarn, M. Xue, J.I. Zink, Inorganic chemistry, 52 (2013) 2044-2049.

[46] M. Gisbert-Garzarán, M. Manzano, M. Vallet-Regí, Bioengineering, 4 (2017) 3.

[47] D. He, X. He, K. Wang, Z. Zou, X. Yang, X. Li, Langmuir, 30 (2014) 7182-7189.

[48] M. Xue, G.H. Findenegg, Langmuir, 28 (2012) 17578-17584.

[49] H. Zheng, Y. Wang, S. Che, The Journal of Physical Chemistry C, 115 (2011) 16803-16813.

[50] C. Gao, H. Zheng, L. Xing, M. Shu, S. Che, Chemistry of Materials, 22 (2010) 5437-5444.

[51] S. Wu, Q. Deng, X. Huang, X. Du, ACS applied materials \& interfaces, 6 (2014) 15217-15223.

[52] H. Zheng, C. Gao, B. Peng, M. Shu, S. Che, The Journal of Physical Chemistry C, 115 (2011) 72307237.

[53] H. Liang, B. Zhou, J. Li, W. Xu, S. Liu, Y. Li, Y. Chen, B. Li, Colloids and Surfaces B: Biointerfaces, 136 (2015) 1224-1233.

[54] R. Casasús, M.D. Marcos, R. Martínez-Máñez, J.V. Ros-Lis, J. Soto, L.A. Villaescusa, P. Amorós, D. Beltrán, C. Guillem, J. Latorre, Journal of the American Chemical Society, 126 (2004) 8612-8613.

[55] D. Jin, J.H. Lee, M.L. Seo, J. Jaworski, J.H. Jung, New Journal of Chemistry, 36 (2012) 1616-1620.

[56] N.N. Sheno, S. Farhadi, A. Maleki, M. Hamidi, New Journal of Chemistry, 43 (2019) 1956-1963.

[57] Z. Shen, H. Wen, H. Zhou, L. Hao, H. Chen, X. Zhou, Materials Science and Engineering: C, (2019) 110073.

[58] R. Rizzuto, P. Pinton, D. Ferrari, M. Chami, G. Szabadkai, P.J. Magalhaes, F. Di Virgilio, T. Pozzan, Oncogene, 22 (2003) 8619.

[59] S. Orrenius, B. Zhivotovsky, P. Nicotera, Nature reviews Molecular cell biology, 4 (2003) 552.

[60] F. Xu, Z. Tang, S. Huang, L. Chen, Y. Liang, W. Mai, H. Zhong, R. Fu, D. Wu, Nature communications, 6 (2015) 7221.

[61] C. Zhou, S. Geng, X. Xu, T. Wang, L. Zhang, X. Tian, F. Yang, H. Yang, Y. Li, Carbon, 108 (2016) 234-241.

[62] H. Wang, X. Li, Z. Ma, D. Wang, L. Wang, J. Zhan, L. She, F. Yang, International journal of nanomedicine, 11 (2016) 1793.

[63] W.-j. Liu, Y.-x. Liu, X.-y. Yan, G.-p. Yong, Y.-p. Xu, S.-m. Liu, Journal of Materials Chemistry A, 2 (2014) 9600-9606.

[64] Y. Fang, D. Gu, Y. Zou, Z. Wu, F. Li, R. Che, Y. Deng, B. Tu, D. Zhao, Angewandte Chemie International Edition, 49 (2010) 7987-7991. 
[65] G. Xu, S. Liu, H. Niu, W. Lv, R.a. Wu, RSC Advances, 4 (2014) 33986-33997.

[66] P. Blackwell, M. Cave, A. Davis, S. Malik, Journal of Chromatography A, 770 (1997) 93-98.

[67] C.Y. Wang, J.G. Tarter, Analytical Chemistry, 55 (1983) 1775-1778.

[68] F. He, C. Shi, Q. Yuan, C. Chen, K. Zheng, Construction and Building Materials, 26 (2012) 1-8.

[69] G. Della Porta, F. Castaldo, M. Scognamiglio, L. Paciello, P. Parascandola, E. Reverchon, The Journal of Supercritical Fluids, 63 (2012) 1-7.

[70] B.J. Berne, R. Pecora, Dynamic light scattering: with applications to chemistry, biology, and physics, Courier Corporation, 2000.

[71] S. Honary, F. Zahir, Tropical Journal of Pharmaceutical Research, 12 (2013) 265-273.

[72] B. Mishra, B.B. Patel, S. Tiwari, Nanomedicine: Nanotechnology, biology and medicine, 6 (2010) 9-24.

[73] K.S. Sing, Advances in Colloid and Interface Science, 76 (1998) 3-11.

[74] J. Rouquerol, F. Rouquerol, P. Llewellyn, G. Maurin, K.S. Sing, Adsorption by powders and porous solids: principles, methodology and applications, Academic press, 2013.

[75] S. Lowell, J.E. Shields, M.A. Thomas, M. Thommes, Characterization of porous solids and powders: surface area, pore size and density, Springer Science \& Business Media, 2012.

[76] J.C. Stockert, R.W. Horobin, L.L. Colombo, A. Blázquez-Castro, Acta histochemica, 120 (2018) 159-167.

[77] M.V. Berridge, P.M. Herst, A.S. Tan, Biotechnology annual review, 11 (2005) 127-152.

[78] N. Zohreh, S.H. Hosseini, A. Pourjavadi, Journal of Industrial and Engineering Chemistry, 39 (2016) 203-209.

[79] L.M. Bareford, P.W. Swaan, Advanced drug delivery reviews, 59 (2007) 748-758.

[80] L.Y. Chou, K. Ming, W.C. Chan, Chemical Society Reviews, 40 (2011) 233-245. 
Declarations of interest: none 


\section{Highlights}

1- Hollow mesoporous carbon nanospheres (HMCNs) were prepared and modified with an oxygen-rich polymer containing pendant imidazole groups.

2- The imidazole groups on the surface of nanocarrier formed $\mathrm{pH}$-sensitive coordination bonds with calcium ions which were used as gate keepers.

3- The oxygen rich polymer on the surface of the nanocarrier increases the hydrophilicity and reduces the toxicity.

4- Large amount of DOX, as a model of hydrophilic anticancer drug, was loaded onto the nanocarrier.

5- The nanocarrier can be applied to delivery of both DOX drug and calcium ions

6- A large amounts of cellular uptake was observed toward HeLa cancer cells. 